\title{
Cysteine and Glutathione Levels in Developing Rat Kidney and Liver
}

\author{
BEATRICE STATES, JOHN W. FOREMAN, AND STANTON SEGAL \\ Children's Hospital of Philadelphia, Departments of Pediatrics and Medicine, University of Pennsylvania School
of Medicine, Philadelphia, Pennsylvania 19104 and Department of Pediatrics, Medical College of Virginia. \\ Richmond, Virginia 23233 [J.W.F.]
}

\begin{abstract}
Intracellular levels of cysteine (CSH) and reduced glutathione (GSH) in the kidney and liver of rats from the newborn to the adult period have been determined using a sensitive high performance liquid chromatography method. In the kidney, the intracellular level of free CSH increased 4-fold from 1 to $4 \mathrm{nmol} / \mathrm{mg}$ protein with $\mathrm{GSH}$ levels which ranged from 20 to $25 \mathrm{nmol} / \mathrm{mg}$ protein from the 10 th to 21 st postnatal day, respectively. In contrast, intracellular free hepatic CSH showed a biphasic pattern with development. Intracellular free hepatic GSH, on the other hand, increased 2-fold over the 3- to 21-day postnatal period. In adult tissues, intracellular levels of free CSH and GSH decreased as compared with levels in 21-day postnatal animals. When ratios of CSH to GSH were compared between tissues from the 3-day-old postnatal and adult rat, CSH:GSH increased approximately 4-fold in the kidney and decreased 2- to 3-fold in the liver. (Pediatr Res 22: 605-608, 1987)
\end{abstract}

\section{Abbreviations}

\author{
CSH, cysteine \\ CSSC, cystine \\ GSH, reduced glutathione \\ GSSG, oxidized glutathione \\ DTNB, 5,5'-dithiobis(2-nitrobenzoic acid) \\ EDTA, ethylene-diaminetetraacetic acid \\ DTT, dithiothreitol \\ TCA, trichloroacetic acid \\ HPLC, high performance liquid chromatography \\ GGTPase, $\gamma$-glutamyltranspeptidase
}

Glutathione is a major cellular reductant with significant roles in catalysis, metabolism, transport, and detoxification of endogenous and exogenous foreign compounds. Both the rate of synthesis and cellular levels of this tripeptide within the cytoplasm of mammalian cells depend upon the availability of its precursor, cyst(e)ine (1). Cyst(e)ine per se is essential for growth and development through its involvement in metabolic processes of protein synthesis and its sparing effect on transsulfuration and transmethylation $(2,3)$. Both thiol compounds, therefore, play major roles in maintaining the homeostasis of the metabolizing cell.

The few data in the literature on cyst(e)ine metabolism with development have dealt mainly with determination of the uptake of labeled cystine and its intracellular conversion to free labeled

Received February 12, 1987; accepted July 9, 1987.

Correspondence Beatrice States, Ph.D. The Children's Hospital of Philadelphia Division of Metabolism, 34th and Civic Center Blvd., Philadelphia. PA 19104.

Supported by Grant AM 10894 from the National Institutes of Health. Bethesda, Md and Grant 841122 from the American Heart Association, Dallas, TX.
CSH and GSH in isolated renal cortical tubule fragments from dog (4) and rat (5) kidneys, and rat kidney cortical slices (6). In these in vitro systems 80 to $90 \%$ of the label was incorporated into intracellular free CSH with approximately $5 \%$ appearing in GSH in both neonatal and adult tissues. Several reports have appeared recently on the effect of metabolic perturbation in the intact rat on intracellular levels of GSH $(1,7)$. The rapid oxidation of GSH to GSSG and the breakdown of the tripeptide to its constituent amino acids, cysteine, glycine, and glutamate, and to the dipeptides, cysteinylglycine, and glutamylcysteine, have resulted in reports of intracellular in vivo levels ranging from 15 to $40 \mathrm{nmol} \mathrm{GSH} / \mathrm{mg}$ intracellular protein. Only recently has quantitation of free CSH per se been possible and only a single report has appeared from this laboratory on the comparative levels of intracellular GSH in renal cortical slices from newborn and adult rats (8). Utilizing a sensitive HPLC method of separation, we have assayed the in vivo levels of free intracellular CSH and GSH in the liver and kidney of the developing rat. Our results comprise the basis of this report.

\section{MATERIALS AND METHODS}

Reagents. CSH·HCl, GSH, DTNB, GSSG, EDTA, and DTT were purchased from Sigma Chemical Co., St. Louis, MO. American Burdick \& Jackson HPLC grade methanol was from American Scientific Products, Edison, NJ. All other reagents were either HPLC grade or AR grade and were obtained through Fisher Scientific, King of Prussia, PA.

Animals. Sprague-Dawley 18-day-pregnant female rats were obtained from Charles River Breeding Laboratories, Wilmington, MA. Each rat was housed separately and upon parturition each litter was limited initially to 10 pups with two pups from each mother being killed by decapitation at the appropriate age for assay of $\mathrm{CSH}$ and GSH. The pups remaining were weaned at 18 days of age. No attempt was made to regiment the feeding of the newborns. The mothers were supplied with water and were fed laboratory rat food ad libitum.

Method of analysis. The HPLC method, a modification of one described by Komuro et al. (9), was performed at room temperature with a Waters model $6000 \mathrm{~A}$ solvent delivery system equipped with a 10 micron $\mu$ Bondapak $C_{18} 3.9 \mathrm{~mm} \times 30 \mathrm{~cm}$ column to which were attached a Waters model U6K injector and a model 440 absorbance detector with dual channel amplifier module, 365 and 254 wavelength analytical cells and photodetector assemblies. The eluate concentrations were recorded on an OmniScribe B-5000 strip chart recorder preset to $100 \%$ scale deflection at 0.005 absorbance units for $365 \mathrm{~nm}$ and $100 \%$ at 0.20 absorbance units for $254 \mathrm{~nm}$. The mobile phase, consisting of $850 \mathrm{ml}$ of $0.2 \mathrm{M}$ HPLC potassium monobasic phosphate adjusted to $\mathrm{pH} 3.0$ with HPLC grade phosphoric acid to which $150 \mathrm{ml}$ of HPLC grade methanol was added, was delivered isocratically by an Autochrom model $111 \mathrm{OPG} / \mathrm{S}$ one pump gradient controller at a flow rate of $0.8 \mathrm{ml} / \mathrm{min}$. 
Preparation of standards. A $1.5 \mathrm{mM}$ stock solution of CSH. $\mathrm{HCl}$ was prepared in $10 \mathrm{ml} 0.01 \mathrm{M}$ EDTA-5\% TCA. This solution was mixed well and a CSH standard prepared with 0.25 $\mathrm{ml}$ of the above CSH stock solution added to $2.50 \mathrm{ml} 0.02 \mathrm{M}$ EDTA, $1.75 \mathrm{ml} \mathrm{H}_{2} \mathrm{O}$, and $0.50 \mathrm{ml} 50 \%$ TCA. Just prior to injection, $1 \mathrm{ml}$ standard CSH was added to $4 \mathrm{ml}$ Tris. $\mathrm{HCl}$ buffer pH 8.9. After addition of $0.1 \mathrm{ml} 10 \mathrm{mM}$ DTNB (prepared in methanol), the mixture was filtered through a $0.22-\mu \mathrm{m}$ filter and injected. The lower limit of sensitivity for CSH was $5 \mathrm{pmol}$. The GSH stock was prepared as a $1 \mathrm{mM}$ solution in $10 \mathrm{ml} 0.01 \mathrm{M}$ EDTA-5\% TCA. Prior to injection, $0.2 \mathrm{ml}$ of the stock GSH was added to $1.8 \mathrm{ml}$ EDTA-TCA, $4.0 \mathrm{ml} 0.4 \mathrm{M}$ Tris. $\mathrm{HCl}$ buffer $\mathrm{pH}$ 8.9 and $0.1 \mathrm{ml} 10 \mathrm{mM}$ DTNB. This GSH standard was filtered also through a $0.22-\mu \mathrm{M}$ filter. The lower limit of sensitivity for GSH was $15 \mathrm{pmol}$. To determine CSSC and oxidized glutathione, stock solutions of the disulfides were prepared in the same manner as their thiol counterparts and were reduced with DTT to CSH and GSH, respectively, as follows: a $0.5-\mathrm{ml}$ aliquot of standard CSSC was added to $4.0 \mathrm{ml}$ Tris $\cdot \mathrm{HCl}$ buffer $\mathrm{pH} 8.9,0.1$ $\mathrm{ml}$ DTT $(6.6 \mathrm{mg} / 10 \mathrm{ml})$, and sufficient $\mathrm{H}_{2} \mathrm{O}$ was added for a total volume of $6 \mathrm{ml}$. With GSSG, a $0.1-\mathrm{ml}$ aliquot of the disulfide was added to $4.0 \mathrm{ml}$ Tris. $\mathrm{HCl}$ buffer $\mathrm{pH} 8.9,0.3 \mathrm{ml}$ DTT, and sufficient $\mathrm{H}_{2} \mathrm{O}$ for a total volume of $5.8 \mathrm{ml}$. After $1 \mathrm{~h}$ with periodic mixing, 0.1 and $0.3 \mathrm{ml}$ of DTNB were added to the reduced CSSC and glutathione standards, respectively. The mixture was filtered and an aliquot injected. Recovery of CSH and GSH added to tissue extracts was essentially $100 \%$ as reported by Komuro et al. (9). Recovery of CSSC as CSH and GSSG as GSH was $100 \%$. The retention times were reproducible with $\mathrm{CSH}$ at $7.5 \mathrm{~min}$, glutamylcysteine at $9.5 \mathrm{~min}$, and GSH at $18 \mathrm{~min}$ (Fig. 1). The peak with a retention time of 11 to $12 \mathrm{~min}$ corresponded to the 2-nitro-5-thiobenzoic acid referred to by Komuro et al. (9).

Tissue preparation. Animals were killed at approximately the same time of day for each study. Within 1 min after the pups were decapitated, the kidneys were removed, decapsulated, minced into small pieces, and placed in cold 0.01 M EDTA- $5 \%$ TCA contained in a $15-\mathrm{ml}$ Kontes dounce homogenizer. A portion of the liver also was removed, minced, and placed in cold $0.01 \mathrm{M}$ EDTA-5\% TCA. Each tissue was homogenized in the cold 10 times with a A (loose) pestle and 10 times with a B

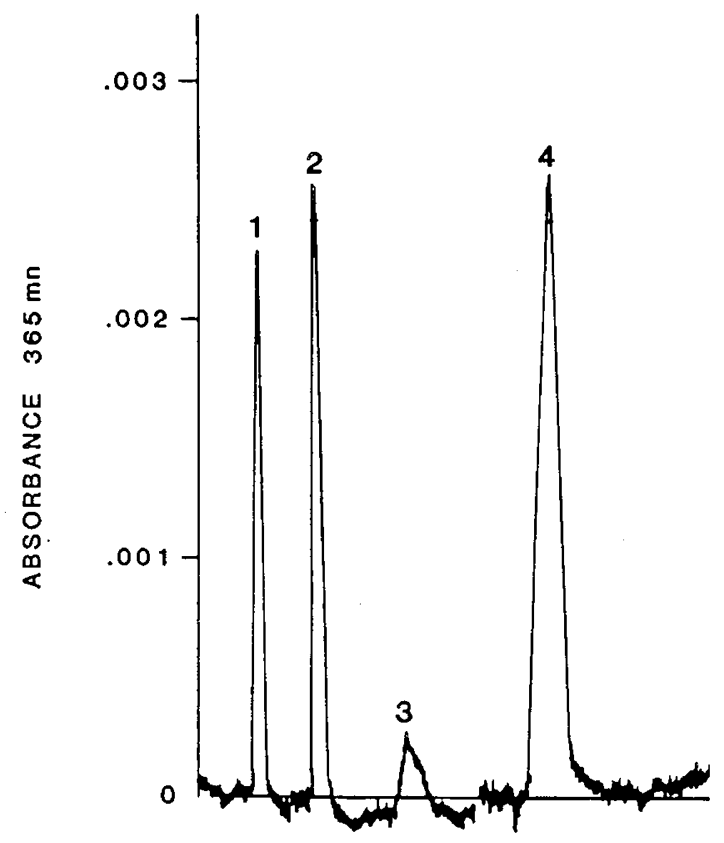

Fig. 1. HPLC chromatography pattern and elution time for $(1) \mathrm{CSH}$, $7.5 \mathrm{~min}$; (2) glutamylcysteine, $9.5 \mathrm{~min}$; (3) 2-nitro-5-thiobenzoic acid, 11-12 min, and (4) GSH, $18 \mathrm{~min}$. (tight) pestle. The homogenates (5-10\% wet weight of tissue/vol) were placed on ice for $15 \mathrm{~min}$ and then were centrifuged at $10,000 \times g$ at $4^{\circ} \mathrm{C}$ for $10 \mathrm{~min}$. After centrifugation, the supernatant was removed and either stored immediately at $-40^{\circ} \mathrm{C}$ for no longer than $1 \mathrm{wk}$ or prepared for immediate assay of CSH and GSH. Levels of free CSH and GSH in the frozen supernatants did not change significantly after $1 \mathrm{wk}$ of storage at $-40^{\circ}$ C. The protein content of the supernatant was determined by the method of Lowry et al. (10).

Preparation of assay samples. Five min before assay $2 \mathrm{ml}$ of the above supernatants were added to $4 \mathrm{ml} 0.4 \mathrm{M}$ Tris $\cdot \mathrm{HCl}$ buffer $\mathrm{pH} 8.9$ followed by $0.1 \mathrm{ml} 10 \mathrm{mM}$ Ellman's reagent (DTNB). The mixtures were shaken periodically for $3 \mathrm{~min}$ and then filtered through a Millex-GS $0.22-\mu \mathrm{m}$ filter unit. A 5- to 20$\mu \mathrm{l}$ aliquot was analyzed immediately for $\mathrm{CSH}$ and GSH.

\section{RESULTS}

Ontogeny of intracellular free CSH and GSH. Figure 2 shows the pattern of intracellular levels of free CSH and GSH in developing kidney and liver. CSSC and GSSG were not present in detectable amounts in either tissue, i.e., less than $0.25 \mathrm{nmol}$ $\mathrm{CSSC} / \mathrm{mg}$ protein and less than $1.5 \mathrm{nmol} \mathrm{GSSG} / \mathrm{mg}$ protein. In the kidney, the intracellular level of free CSH stayed constant at about $1 \mathrm{nmol} / \mathrm{mg}$ protein for 10 days and then increased significantly $(p<0.001)$ to $4 \mathrm{nmol} / \mathrm{mg}$ protein by 21 days. The latter level was also found in adult kidney. In contrast, the level of intracellular free GSH showed a biphasic pattern with a significant $(p<0.001)$ increase from $11.84 \pm 1.08$ (SEM) to $25.85 \pm$ $0.93 \mathrm{nmol} / \mathrm{mg}$ protein from term to the $3 \mathrm{rd}$ postnatal day, respectively. By the 7th day, intracellular free GSH levels had fallen to $19.78 \pm 1.07 \mathrm{nmol} / \mathrm{mg}$ protein. Free intracellular GSH levels plateaued from the 7 th through the 14 th day. On day 21 ( 3 days after the pups were weaned), the intracellular GSH levels had increased to $27.15 \pm 2.92 \mathrm{nmol} / \mathrm{mg}$ protein. In the kidney of the mature animal, the quantity of intracellular free CSH did not differ significantly from that found in the 21 day old;

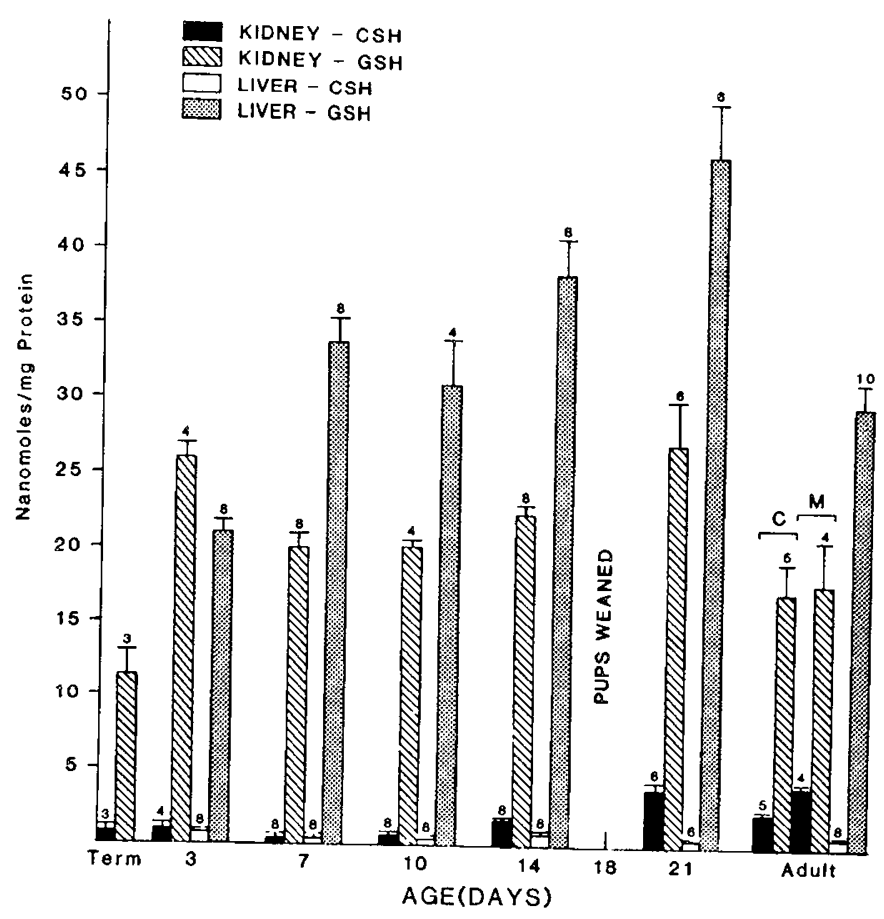

Fig. 2. Intracellular levels of free CSH and GSH in developing kidney and liver. Tissue preparation and method of assay are described in "Materials and methods." Each bar represents the mean value \pm SEM of indicated number of determinations. $C$, kidney cortex; $M$, kidney medulla. 
however, intracellular free GSH had returned to a level which did not significantly differ from that found in the kidneys from the 7- to 14-day-old animals.

Figure 2 also shows the levels of intracellular free $\mathrm{CSH}$ and GSH in developing liver. Intracellular hepatic free CSH was less than $1.0 \mathrm{nmol} / \mathrm{mg}$ protein in the neonate and adult rat. In contrast to increasing free kidney $\mathrm{CSH}$, hepatic $\mathrm{CSH}$ levels presented a biphasic pattern during liver development (Fig. 2). In the beginning, free $\mathrm{CSH}$ was relatively high [i.e. day 3 at 0.84 $\pm 0.13(\mathrm{SEM}) \mathrm{nmol} / \mathrm{mg}$ protein]. The day-3 CSH value differed significantly $(p<0.01)$ from the decreased level of $0.47 \pm 0.03$ $\mathrm{nmol} / \mathrm{mg}$ protein found on the 10 th postnatal day. From days 10 to 14 , free CSH rose significantly $(p<0.01)$ to $0.79 \pm 0.09$ $\mathrm{nmol} / \mathrm{mg}$ protein. From the 14 th postnatal day until the animals matured, hepatic free CSH decreased from 0.79 to $0.34 \pm 0.04$ $\mathrm{nmol} / \mathrm{mg}$ protein $(p<0.001)$. Intracellular free GSH, however, showed a different pattern of development with the lowest level of $21.05 \pm 0.99 \mathrm{nmol} / \mathrm{mg}$ protein present in the 3-day-old rat (Fig. 2). From the 3rd to the 7th postnatal day, free hepatic GSH increased significantly to $33.72 \pm 1.79 \mathrm{nmol} / \mathrm{mg}$ protein $(p<$ $0.001)$. The upsurge in free GSH over this early neonatal period was followed by a plateauing of intracellular GSH from the $7 \mathrm{th}$ to 10 th postnatal days. From the 10 th to 21 st day after term, intracellular free GSH rose significantly from $30.78 \pm 3.71$ to $46.39 \pm 3.91 \mathrm{nmol} / \mathrm{mg}$ protein, respectively $(p<0.001)$. Weaning of pups on the 18 th day may have had a pronounced affect on the elevated GSH observed on the 21 st postnatal day (11). Free hepatic GSH then decreased from 46.39 on the 21 st day after term to $29.28 \pm 1.44 \mathrm{nmol} / \mathrm{mg}$ protein in adult liver $(p<$ $0.01)$.

Comparison of CSH:GSH in developing kidney and liver. The synthesis of GSH in vivo is dependent, in part, on the availability of precursor, CSH $(1,12,13)$. To obtain a better understanding of the relation between the intracellular free levels of these two thiols during development, the ratios of CSH:GSH were calculated. In the kidney, the ratio of $\mathrm{CSH}$ to GSH remained constant at approximately 0.04 from the 3 rd to the 10 th postnatal day. From day 10 to day 21 , however, the ratio increased 3.6 -fold to 0.14 , respectively. The CSH:GSH ratios in the 3 -day-old neonate were not significantly different in liver and kidney. However, instead of increasing as in the kidney, liver ratios decreased gradually from 0.04 on the 3 rd postnatal day to 0.01 in the 21 day old. In order to show more clearly the differences in
$\mathrm{CSH}$ GSH between developing kidney and liver, the ratio of the 3 day old was selected as the common denominator for comparison of changing CSH:GSH with development. These calculations (Fig. 3) show the following: (I) in the kidney (a) the ratio of $\mathrm{CSH}$ to GSH remained constant from the 3rd to the 10th postnatal day and (b) from the 10th to 21 st days the ratios increased 3.6 fold; (II) in the liver (a) the ratio decreased more than $50 \%$ from the 3 rd to 7 th day and (b) the ratios continued to decrease gradually from the 10 th through 21 st postnatal day resulting in a ratio in the 21 day old which approximated $25 \%$ of that calculated for the 3-day-old neonate.

\section{DISCUSSION}

Glutathione and $\mathrm{CSH}$ are two important intracellular thiols. Glutathione plays a vital role in a number of fundamental cellular processes, not the least of which is protection from oxidative stress. The amino acid, CSH, is an important constituent of most proteins, determining the tertiary structure through disulfide bridges. Further, CSH is one of the three amino acids; CSH, glycine, and glutamate, which make up glutathione. It is the sulfhydryl group of CSH which allows glutathione to perform its reducing function.

In the immature animal the activity of the enzyme cystathionase, important in converting the essential amino acid methionine to $\mathrm{CSH}$, is low $(14,15)$. This has led some investigators to question whether $\mathrm{CSH}$ may be an essential amino acid in the newborn (14). Because of this question and the importance of these thiols in cellular metabolism, we examined the intracellular content of $\mathrm{CSH}$ and GSH in the developing rat.

In the kidney, CSH remained low throughout the nursing period, but rose by $3 \mathrm{wk}$ of age in concert with weaning. GSH rose to adult levels by the 3 rd day of life falling somewhat by the end of the lst postnatal wk. With the onset of weaning, GSH rose again and then returned to a level similar to that of the 1 wk old.

In the liver, the intracellular $\mathrm{CSH}$ was much lower than that found in the kidney throughout development and this difference was most marked after weaning when the CSH content of the kidney went up significantly. Also in contrast to the kidney, the highest $\mathrm{CSH}$ levels were noted soon after birth. However, this elevated CSH fell $44 \%$ by the 10 th day of life. From the 10 th to

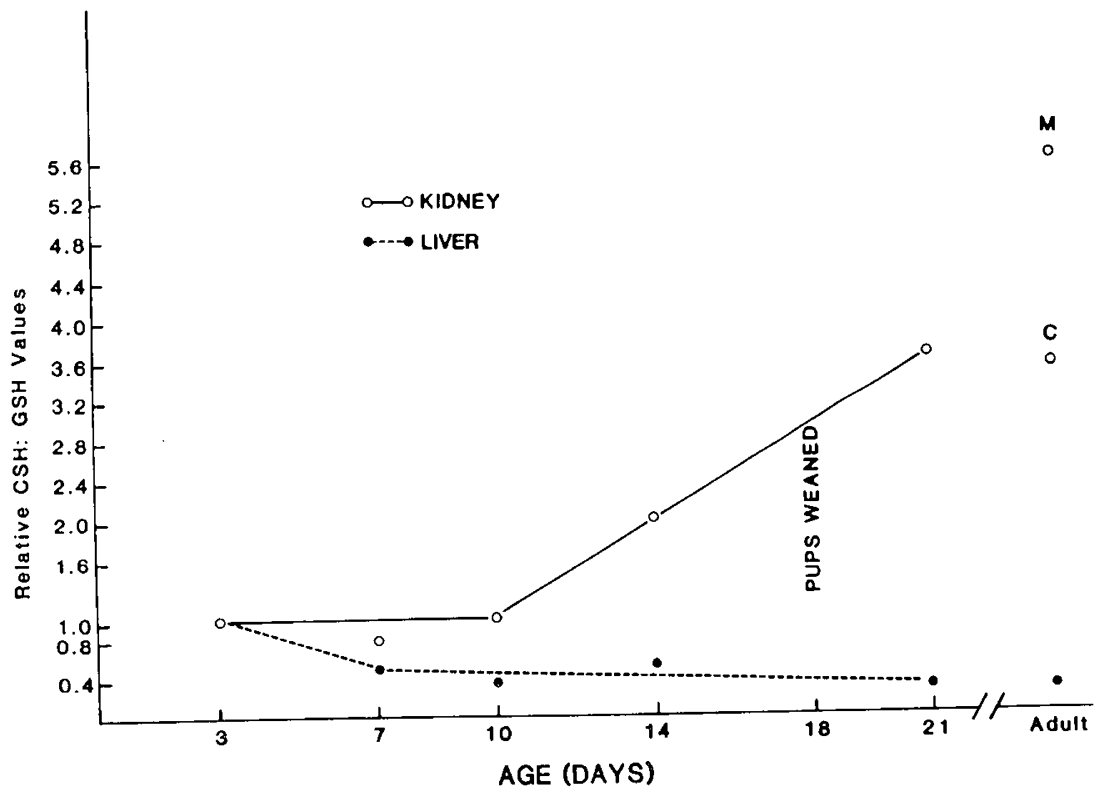

Fig. 3. Comparison of relative ratios of $\mathrm{CSH}$ to GSH in kidney and liver based on tissues from 3-day-old rats. 
the 14th day of life, the CSH content rose to a level similar to the 3 day old, but then it fell again by $57 \%$ with maturity. GSH, on the other hand, rose during the nursing period and peaked with weaning. It then fell with attainment of adulthood to levels comparable to the 2 nd wk of life.

The intracellular levels of these thiols are dependent on numerous factors, many of which have not been well characterized. Obviously the balance between synthesis and degradation or use is an important determining factor of these levels. The activity of cystathionase, an enzyme in the transsulfuration pathway converting methionine to $\mathrm{CSH}$, is low in the neonate, limiting $\mathrm{CSH}$ synthesis, but rises with development $(14,15)$. Other influences are dietary intake and movement into and out of the cells in the kidney and liver. CSSC, the circulating form of $\mathrm{CSH}$, is rapidly taken up by immature rat renal tubule cells at a rate comparable to the adult, while movement out of the cell appears to be slower (5). Whether development of the liver affects CSSC or CSH uptake is not known.

More is known about glutathione synthesis and degradation. Gamma-glutamylcysteine synthetase activity in the kidney appears earlier (16) than the activity of GGTPase (17), the degradative enzyme. This is consistent with our findings of a higher GSH level in the kidney at 3 days of life compared to later values, except for just after weaning. In the liver, GGTPase activity is highest at birth and then declines (18). Further, the activity of this enzyme in liver is quite low compared to kidney leading to the hypothesis that GSH is principally formed in the liver and degraded at extrahepatic sites, such as the kidney (18). However, at this time not enough is known about the developmental pattern of the hepatic GSH synthesizing enzymes to interpret the pattern of hepatic GSH levels we have observed. Further research is needed examining the changes in these enzymes, as well as GSH turnover rates, in developing animals to understand fully the influences governing these intracellular levels.

\section{REFERENCES}

1. Kaplowitz N, Aw TY, Ookhtens M 1985 The regulation of hepatic glutathione. Ann Rev Pharmacol Toxicol 25:715-744

2. Finkelstein JD, Martin JJ, Harris BJ 1986 Effect of dietary cystine on methionine metabolism in rat liver. J Nutr 116:985-990

3. Hirakawa DA, Baker DH 1985 Sulfur amino acid nutrition of the growing puppy: determination of dietary requirements for methionine and cystine. Nutr Res 5:631-642

4. Foreman JW, Medow MS, Bovee KC, Segal S 1986 Development aspects of cystine transport in the dog. Pediatr Res 20:593-597

5. Hwang SM, Foreman J, Segal S 1982 Developmental pattern of cystine transport in isolated rat renal tubules. Biochim Biophys Acta 690:145-153

6. Segal S, Smith I 1969 Delineation of separate transport systems in rat kidney cortex for L-lysine and L-cystine by developmental patterns. Proc Natl Acad Sci USA 63:926-933

7. Aw TY, Ookhtens M, Kaplowitz N 1984 Inhibition of glutathione efflux from isolated rat hepatocytes by methionine. J Biol Chem 259:9355-9358

8. Roth KS, Serabian MA, Rea C, Segal S 1980 Developmental and diamideinduced differences in rat renal cortical glutathione levels. Proc Soc Exp Biol Med 163:91-94

9. Komuro C, Ono K, Shibamoto Y, Nishidai T, Takahashi M, Abe M 1985 Rapid and simple method for quantitative determination of non-protein sulphydryls in mouse liver by reversed-phase high-performance liquid chromatography. J Chromatogr 338:209-212

10. Lowry OH, Rosebrough NJ, Farr AL, Randall RJ 1951 Protein measurement with the folin phenol reagent. J Biol Chem 193:265-275

11. Larson A, Orrenius S, Holmgren A, Mannervik B (eds) 1983 Functions of Glutathione. Biochemical Physiological Toxicological and Clinical Aspects. Raven Press, New York

12. Bannai S, Tateishi N 1986 Role of membrane transport in metabolism and function of glutathione in mammals. J Membr Biol 89:1-8

13. Griffith ow 1981 The role of glutathione turnover in the apparent renal secretion of cystine. J Biol Chem 256:12263-12268

14. Sturman JA, Gaull G, Raiha NCR 1970 Absence of cystathionase in human fetal liver: Is cystine essential? Science 169:74-75

15. Alotkin SH, Anderson GH 1982 The development of cystathionase activity during the first year of life. Pediatr Res 16:65-68

16. Tsui E, Yeung D 1979 Development of gamma-glutamylcysteine synthetase and oxoprolinase in rat kidney. Experientia 35:1293-1294

17. Tate SS, Meister A 1975 Identity of maleate-stimulated glutaminase with gamma-glutamyl transpeptidase in rat kidney. J Biol Chem 250:4619-4627

18. Taniguchi M, Inoue M 1986 Ontogenic changes in metabolism and transport of glutathione in the rat. J Biochem 100:1457-1463 